\title{
Progress on the Development of APS Beam Position Monitoring System*
}

\author{
Glenn Decker and Youngjoo Chung \\ Advanced Photon Source \\ Argonne National Laboratory \\ Argonne, IL, 60439
}

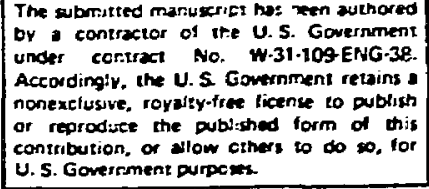

Abstract- This paper describes the development stalus of the beam position monitoring system for the Advanced Photon Source (APS), a third-generation light source now under construction at Argonne National Laboratory. The accelerator complex will consist of an electron linac, a positron linac, a positron accumulator ring (PAR), an injector synchrotron and a storage ring. For beam position measurement, striplines will be used on the linacs, while button-type pickups will be used on the injector synchrotron and the storage ring. A test stand with a prototype injector synchrotron beam position monitor (BPM) unit has been built, and we present the results of position calibration measurements using a wire. Comparison of the results with theoretical calculations will be presented. The current effort on similar storage ring BPM system measurements will also be discussed

\section{Introduction}

The Advanced Photon Source storage ring at Argonne is designed to operate at $7 \mathrm{GeV}$ with an operating current of $100 \mathrm{~mA}$, and has a circumference of 1104 meters. Along :his circumference will be placed 360 beam position monitoring stations, each composed of four button-type capacitive pickup electrodes. The injector synchrotron, which is exactly one third the circumference of the storage ring, has BPMs that are also of the button-type, and a total of 80 stations are planned.

Ultimately, a measurement accuracy of $\pm 200 \mu \mathrm{m}$ for the storage ring is required relative to the magnetic centerline of adjacent sextupole magnets, with a required resolution of better than $25 \mu \mathrm{m}$. The reason for the tight accuracy specification is that, at commissioning, the dynamic aperture of the machine approaches the physical aperture when the ms placement error of the sextupole magnets is equal to $200 \mu \mathrm{m}$. After commissioning, the insertion device vacuum chambers $(1.2 \mathrm{~cm}$ vertical full aperture) will be installed and become the limiting aperture.

In addition to measuring the beam position of stored positron beams, the BPM system must have a first turn capability for commissioning. The accuracy specification for the storage ring BPM measurement in first tum mode is

- Work supported by the U.S.Department of Energy. Office of Basic Energy Sciences, under Contract No. W-31-109. ENG-38. $\pm 500 \mu \mathrm{m}$ with a resolution better than $\pm 200 \mu \mathrm{m}$. At this time, it is planned to also incorporate tum by tum capability in both the storage ring and injector synchrotron designs. Accuracy and resolution specifications for the injector synchrotron are $\pm 500 \mu \mathrm{m}$ and $\pm 100 \mu \mathrm{m}$, respectively.

\section{Beam Position Monitor Mechanical Design}

The pickup electrode design is similar to that developed at ESRF in Grenoble, France, and being used in the Elettra machire in Trieste, Italy. A high vacuum feedthrough with a small (.425" dia.) button attached on the vacuum side is welded into a 1.33" diameter flange. Alumina $\left(\mathrm{Al}_{2} \mathrm{O}_{3}\right)$ is used to insulate the center pin of the feedthrough and provide a good RF match. The flange is machined to accept a Helicoflex vacuum seal. Mounting the feedthroughs on individual flanges allows convenient replacement of defective units. Specifications for the pickup electrodes to be used in both the storage ring and injector synchrotron are shown in Table 1.

Table 1 BPM Feedthrough Specifications

\begin{tabular}{|c|c|}
\hline He. Leak Rate & $<10^{-10}$ atm-oc/sec. \\
\hline Bakeable to & $400^{\circ} \mathrm{C}$ \\
\hline VSWR @ 6 GHz (12 GHz) & $\leq 1.04(1.08)$ \\
\hline Dielectric Strength @ 60 Hz & $\geq 1500$ Volts \\
\hline
\end{tabular}

Two complete injector synchrotron BPM prototypes, each having four button-type pickup electrodes, were fabricated for electrical testing. One such device is shown in Figure 1. The BPM was machined from a solid block of AISI 316L stainless steel using a wire EDM technique in combination with NC machining. The inner bore is elliptical with major axis $3 \mathrm{~cm}$ and minor axis $1.85 \mathrm{~cm}$. The overall length of each prototype is $10.2 \mathrm{~cm}$.

The storage ring vacuum chamber is an aluminum extrusion with a roughly elliptical inner bore near the positron beam, a photon exit slot, and an antechamber conlaining NEG pumping strips [1]. The pickup electrodes will be mounted on machined flals surrounding the positron side of the chamber. They will be located with a tolerance of $\pm .004^{\prime \prime}( \pm 100 \mu \mathrm{m})$ relative to the positron chamber center.

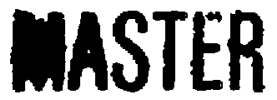




\section{DISCLAIMER}

This report was prepared as an account of work sponsored by an agency of the United States Governinent. Neither the United States Government nor any agency thereof, nor any of their employees, makes any warranty, express or implied, or assumes any legal liability or responsibility for the accuracij, completeness, or usefulness of any information, apparatus, product, or process disclosed, or represents that its use would not infringe privately owned rights. Reference herein to any specific commercial product, process, or service by trade name, tradematk. manufacturer, or otherwise does not necessarily constitute or imply its endorsement, recommendation, or favoring by the United States Government or any agency thereor. The views and opinions of authors expressed herein do not necessarily state or reflect those of the United States Government or any agency thereof. 


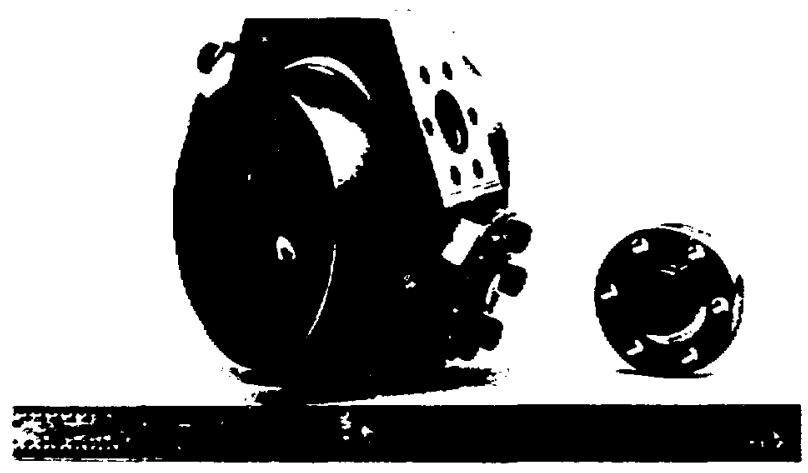

Flgure 1. Injector Synchrotron BPM

\section{BPM Electrical Characterization}

The electrical characterization of BPM assemblies consists of measuring button capacitance, calibrating the assembly using a coaxial wire technique, and finally extracting electrical offsets from button to button transfer function measurements for comparison with those determined using the wire calibration. The final step provides the possibility of determining offsets under vacuum in the final configuration using only the buttons themselves and their associated cabling.

\section{A. Button Capacitance Measurement}

A time domain reflectometer technique was used to measure button capacitance. The time constant of the exponential reflected waveform resulting from a step function input yields the capacitance according to $\tau=R C$, where $R$ is the characteristic impedance of the coaxial line, $50 \Omega$. A linear least squares fit to the logarithn of the data accurately detemines $\tau$.

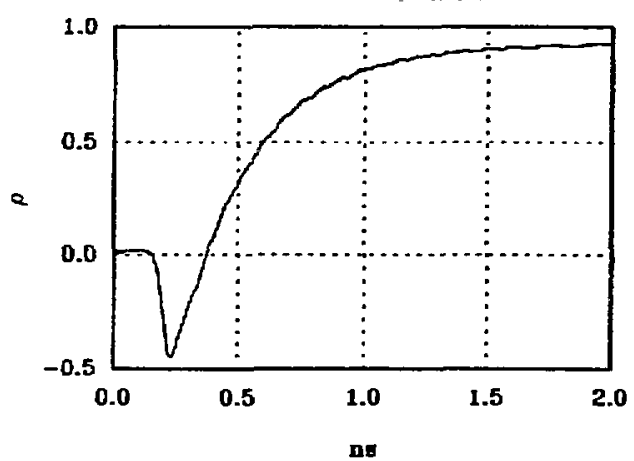

Flgare 2. Button Pickup TDR Messurement

Shown in Figure 2 are data obtained in this way. Notice the absence of any parasitic resonances, indicating that the button is a pure capacitor up to very high frequencies. The TDR rise time was less than 20 ps for this measurement.

Typical results of the technique showed that a button capacitance of approximately 5 pf could be measuned with a standard deviation for random errors of $\pm .05 \%$, or $\pm 2.5 \mathrm{fem}$ tofarads. Disconnecting and reconnecting the button from the cable would typically shif the measured capacitance by about 10 femtofarads. Using a different SMA F-F adaptor moved the measured value by $4 \%$, presumably because of the change in characteristic impedance of the line, which was assumed to be exactly $50 \Omega$.

\section{B. Coaxial Wire Calibration}

Shown in Figure 3 is the test stand used for calibration of the injector synchrotron BPM's. The BPM block was mounted on an $x-y$ translation stage, with a .012" dia steel music wire strung coaxially. Both eads of the wire were attached to SMA bulkhead connectors. A 4:1 ferrite impedance transformer and $133 \Omega$ parallel trimming resistor were used on the input to approximately match the $50 \Omega$ input line to the $320 \Omega$ wire/chamber impedance. On the output, a $270 \Omega$ carbon resistor was placed in series to malch into the $50 \Omega$ output line. This matching scheme proved adequate over the range $\mathrm{DC}-400 \mathrm{MHz}$.

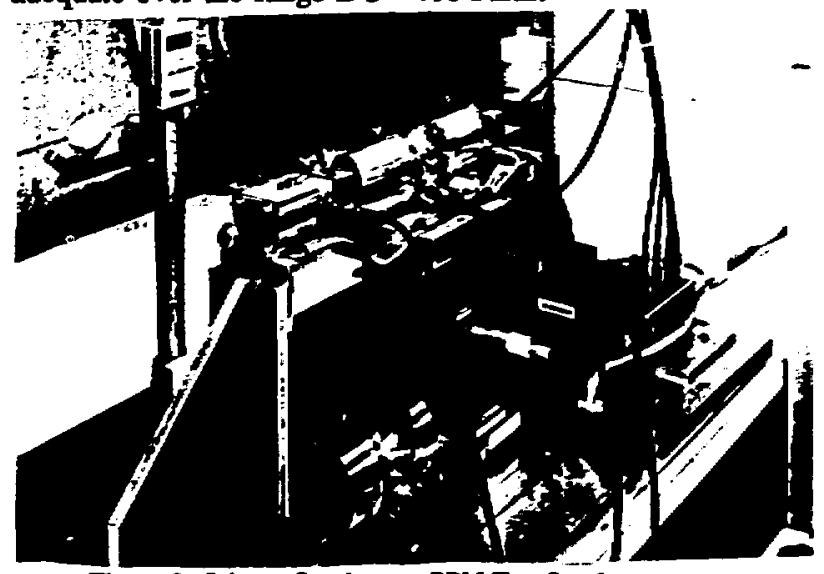

Fleare 3. Injector Synchrotron BPM Teat Seand

A spring tensioning device was located on the left hand side, and on the right was a manual $x-y$ stage for precise wire alignment. During data collection, aluminum foil RF shields were wrapped around the elliptical ends of the BPM block, to sithin about $0.5^{\prime \prime}$ of the ends of the wire, extending the elliptical transverse profile.

The buttons were multiplexed in a mechanical SP4T switch shown at lower right. Calibration was performed at the APS RF frequency, $351.92 \mathrm{MHz}$, using a network analyzer. Button voltages ("A") were normalized using the transmitted RF waveform ("R") coming out the right band side of the test stand (producing "A/R"). Because the $270 \Omega$ series resistor provides a reasonable $R F$ match, the current flowing into the network analyzer " $R$ " input is essentially the same as that flowing on the wire. Therefore the coupling impedance, defined as the button output voltage into $50 \Omega$ divided by the beam current (or wire current), is simply the fraction "A/R" multiplied by $50 \Omega$. 


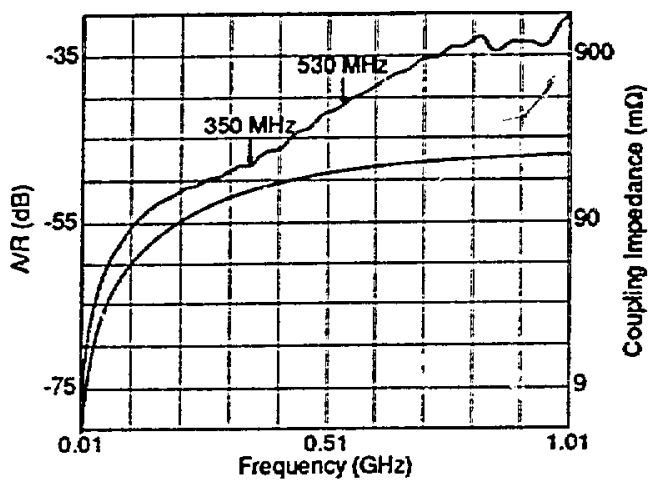

Figure 4. Injector Synchrotron BPM Coupling Impedance

S'sown in Figure 4 is the measured coupling impedance of the injector synchrotron BPM over the frequency range $10 \mathrm{MHz}$ to $1.01 \mathrm{GHz}$ for a typical button with the wire centered. The smooth curve in Figure 4 is the theoretical coupling impedance [2]. The expected $3 \mathrm{~dB}$ point, $1 / 2 \pi R C$, is at about $530 \mathrm{MHz}$ in this case. The high frequency data is an overestimate, simply because the $270 \Omega$ resistor provides a poorer match at high frequency, making " $R$ " smaller, and "A/R" larger.

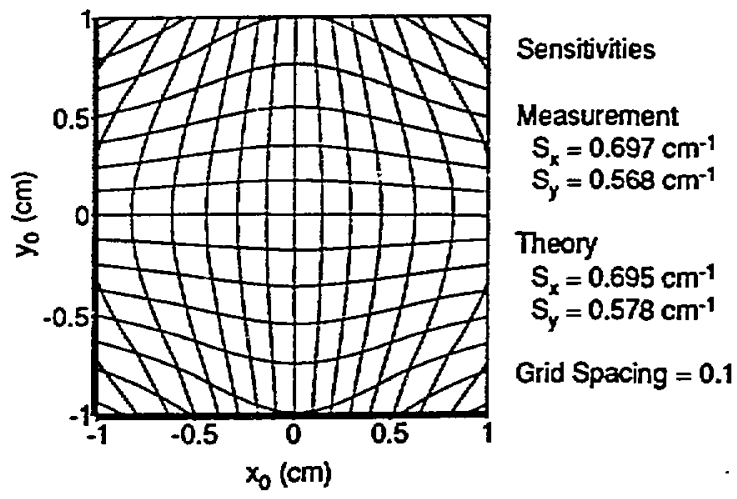

Flyare 5. Injector Symchrotron BPM Calibration Measurement

In Figure 5 is shown a contour plot of measured data from the test stand. Plotted as a function of transverse wire position $x_{0}$ and $y_{0}$ are the quantities $\Delta_{y} \sqrt{\Sigma}$ and $\Delta_{x} \sqrt{\Sigma}$, where $\Sigma$ is the sum of the four button voltages, $\Delta$, is the difference between the top and bottom pairs of button voltages, and $\Delta_{x}$ is the difference between left and right hand pairs. Here $x$ and $y$ take on the usual accelerator conventions (note that Figures 1 and 3 show the monitor rotated by 90 degrees relative to its final installed orientation). The data are in agreement with theoretical calculations to $\pm .0043 \Delta_{\mathrm{y}} \sqrt{\Sigma}$ units and $\pm .0033 \Delta_{x} / \Sigma$ units $\mathrm{ms}[2]$.

\section{Button-Button Transfer Function}

The beam position monitor test stand described in the previous section for APS injector synchrotron BPM calibration was also used as a test bed to determine the accuracy and reliability of a technique pioneered at Beikeley by Lambertson [3] and Hinkson [4] for the determination of electrical offsets by non-invasive means. By measuring the twelve button to button transfer functions between the four button pickups, ratios of relative gains can be extracted, equivalent to electrical offset determination. Using this technique, Hinkson has shown offset determination with an accuracy of better than $\pm 100 \mu \mathrm{m}[4]$.

Shown in Table 2 are comparisons between offsets determined using the wire and using the Lambertson button-button transfer function method with the APS injector synchrotron BPM shown in Figure 1. Three button configurations were cbaracterized; starting from configuration 1 , the pickups were transposed across the $x$ plane (config. 2), and then the y plane (config. 3).

\section{Table 2 Comparison of Offset Data ( $\mu \mathrm{m}$ )}

\begin{tabular}{|c|c|c|c|c|}
\hline Config. & \multicolumn{1}{|c|}{$x_{*}$} & $y_{w}$ & $x_{L}^{*}$ & $y_{L}$ \\
\hline \hline 1 & $-150 \pm 6$ & $103 \pm 13$ & -159 & 100 \\
\hline 2 & $-167 \pm 4$ & $185 \pm 4$ & -152 & 194 \\
\hline 3 & $81 \pm 4$ & $189 \pm 6$ & 73 & 189 \\
\hline
\end{tabular}

* Typ. Meas. errors were $\leq 3 \mu \mathrm{m}$.

The relative button voltages caused by a current flowing on a mechanically centered wire determines the "true" electrical offsets. The ordered pair $\left(x_{w}, y_{w}\right)$ is, by definition, the displacement of the mechanical center relative to the electrical center, measured using the wire technique. The values $x_{L}$ and $y_{L}$ are similariy defined for the buttonbutton transfer function technique. For both measurements the SP4T RF switch was used. Its insertion loss was measured and corrections were made to the data.

\section{Conclusion}

Calibration of the APS injector syachrotron BPM pickups are complete, and results agree well with theory. The technique developed by Lambertson and Hinkson for non-intrusive electrical offset determination shows promise of working down to the $25 \mu \mathrm{m}$ level or better. This has been tested using the slotted Berkeley ALS chamber by Hinkson and will be investigated further with the APS storage ring BPM test stand which is under construction.

\section{Acknowledgements}

Thanks go to Lester Erwin for putting together the test stand, and to Dan Ciarlete for his work on graphics.

\section{References}

[1] R.C. Niemann et. 1.."APS Storage Ring Vacuum System Development", these proceedings

[2] Y. Chung. "Theoretical Studies on the Beam Position Measurement with Button-type Pickups in APS", thewe proceedings.

[3] G.R. Lambertson, "Calibration of Position Electrodes using Extemal Measurements", Lawrence Berkeley Laboratory. LSAP Nore-5, 1987.

[4] J. Hinkson, Lawrence Berkeley Laboratory, private communication. 